\title{
Heterosis effects on photosynthesis of upland cotton (Gossypium hirsutum) hybrid cultivars
}

\author{
H. ZHOU* (D) , Y. ZHANG*, W.Q. DONG*, X.M. XU*,+, and C.M. TANG*,+ \\ State Key Laboratory of Crop Genetics and Germplasm Enhancement, College of Agriculture, Nanjing \\ Agricultural University, 210095 Nanjing, China* \\ College of Life Science, Nanjing Agricultural University, 210095 Nanjing, China**
}

\begin{abstract}
The relationship between the environment and heterosis effects on the photosynthesis of upland cotton (Gossypium hirsutum) is unknown. No significant differences for net photosynthetic rate $\left(P_{\mathrm{N}}\right)$, stomatal conductance $\left(g_{\mathrm{s}}\right)$, and transpiration rate $(E)$ were found between two studied cotton varieties Siza 3 and Zhongmiansuo 48 . The $P_{\mathrm{N}}$ and $g_{\mathrm{s}}$ of Siza 3 demonstrated heterosis compared with its parents. The higher the effective photosynthetic radiation and $\mathrm{CO}_{2}$ concentration were, the more obvious the over better-parent heterosis $(\mathrm{OH})$ of the $P_{\mathrm{N}}$ was. The photosynthesis parameters of Zhongmiansuo 48 in different environments did not display obvious $\mathrm{OH}$, but the $P_{\mathrm{N}}$ of Siza 3 was higher than that of Zhongmiansuo 48. The performance index of the absorption $\left(\mathrm{PI}_{\mathrm{abs}}\right)$ of Siza 3 was higher than that of Zhongmiansuo 48. The $\mathrm{PI}_{\text {abs }}$ was significantly related to the $\mathrm{OH}$ of the $P_{\mathrm{N}}$. The $\mathrm{OH}$ of the $P_{\mathrm{N}}$ of hybrid cotton can be predicted via the $\mathrm{PI}_{\mathrm{abs}}$ under high temperature and light.
\end{abstract}

Keywords: environmental factor; fluorescence; light intensity; photosystem II.

\section{Introduction}

Cotton is the main economic crop in China, and hybrids are widely planted due to their high yields (Xing 2007, Fu et al. 2015). As such, utilizing cotton heterosis has become an effective way to increase yields significantly, improve fiber quality, and enhance disease resistance in cotton (Zhu et al. 2011, Ge et al. 2016). Leaf gas-exchange trait such as photosynthetic rate is the key for the assimilation of photosynthates in plants and enhancement of physiological process may have positive impact on yield in cotton.
The heterosis effects on the net photosynthetic rate $\left(P_{\mathrm{N}}\right)$ differ in different varieties and at different growth stages. Current scenario of climate change such as high temperature requires development of new cotton hybrids with improved leaf gas-exchange parameters. A study showed that cotton hybrid Xiangzamian 3 had high $P_{\mathrm{N}}$ which was not affected by high intensity of light, temperature, and low humidity (Zeng et al. 2012). High temperature causes significant yield losses in cotton; some predictions suggested that cotton yields may decrease by $110 \mathrm{~kg} \mathrm{ha}^{-1}$ by every $1^{\circ} \mathrm{C}$ increment in temperature from

\section{Highlights}

- The $P_{\mathrm{N}}$ and $\mathrm{PI}_{\text {abs }}$ of Siza 3 was higher than that of Zhongmiansuo 48

- The $\mathrm{PI}_{\mathrm{abs}}$ was significantly related to the $\mathrm{OH}$ of the $P_{\mathrm{N}}$

- The $\mathrm{OH}$ of the $P_{\mathrm{N}}$ in hybrid cotton can be predicted by measuring the $\mathrm{PI}_{\mathrm{abs}}$ under high-temperature and high-light conditions
Received 27 April 2020

Accepted 19 November 2020

Published online 12 February 2021

${ }^{+}$Corresponding author

e-mail: xuxm@njau.edu.cn (X.M.Xu) tangcm@njau.edu.cn (C.M. Tang)

Abbreviations: $C_{\mathrm{i}}$ - intercellular $\mathrm{CO}_{2}$ concentration; $C_{\text {isat }}-\mathrm{CO}_{2}$-saturation point; $E$ - transpiration rate; $\mathrm{F}_{0}$ - original fluorescence; $\mathrm{F}_{\mathrm{v}} / \mathrm{F}_{\mathrm{m}}$ - maximal photochemical efficiency; $g_{\mathrm{s}}$ - stomatal conductance; $I$ - photosynthetically active radiation; $\mathrm{I}_{\mathrm{c}}$ - light-compensation point; $\mathrm{I}_{\mathrm{m}}$ - light-saturation point; NPQ - nonphotochemical quenching; $\mathrm{OH}$ - over better-parent heterosis; $\mathrm{PI}_{\mathrm{abs}}$ - performance index of absorption; $P_{\max }-$ maximum photosynthetic rate; $P_{\mathrm{N}}-$ net photosynthetic rate; $P_{\mathrm{Nmax}}-$ light-saturated net photosynthetic rate; $\mathrm{q}_{\mathrm{P}}-$ photochemical quenching coefficient; $R_{\mathrm{D}}$ - dark respiration rate; $\mathrm{RH}$ - relative humidity; $R_{\mathrm{P}}-$ photorespiration rate; $\mathrm{T}_{\text {air }}-$ air temperature; $\mathrm{V}_{\mathrm{k}}$ - fluorescence intensity at the K-step; VPD - vapor pressure deficit; $\Gamma-\mathrm{CO}_{2}$-compensation point.

Acknowledgments: This work was financially supported by the National Key R \& D Program of China (2016YFD0102105) and Jiangsu Postgraduate Research and Practice Innovation Project (KYCX20_0582).

Conflict of interest: The authors declare that they have no conflict of interest. 
$40^{\circ} \mathrm{C}$ in the field (Wang et al. 2017). High temperature is the most important environmental factor affecting plant growth and development (Wang et al. 2016). Under drought conditions, stomata are closed, and the $\mathrm{CO}_{2}$ uptake is reduced, which affects the rate of photosynthesis and reduces growth and yield (Chaves et al. 2009, Liu et al. 2014). However, stomatal conductance $\left(g_{\mathrm{s}}\right)$ is not always related to the $P_{\mathrm{N}}$, although this relationship still needs clarification (von Caemmerer et al. 2004, Xu et al. 2010). However, relationships between the photosynthetic rate and $\mathrm{CO}_{2}$ concentration in cotton have rarely been reported. Most of the photosynthesis performance indicators need to be measured with instruments such as the $L I-6400$ portable photosynthesis system analyzer (Zhao et al. 2017). Although this instrument is large, it provides a convenient means to perform measurements and is highly efficient. The Handy PEA instrument, which is used to measure chlorophyll (Chl) fluorescence, is small and portable and easy to operate. However, it has many different parameter settings, and complicated analysis of the data is needed (Wu et al. 2019). The relationship between the $\mathrm{CO}_{2}$ response and photosynthetic light response, the relationship between photosynthetic rate and $\mathrm{Chl}$ fluorescence parameters, and the effects of heterosis on performance characteristics of these parameters have not been studied in cotton. Zhongmiansuo 48 and Siza 3 are two high-yielding hybrids widely used in China. However, it has not been reported whether there are effects of heterosis on photosynthesis performance. In this study, these two upland cotton hybrids and their parents were used to study parameters measured by the LI-6400 portable photosynthesis system analyzer, the effects of heterosis on Chl fluorescence parameters, and their relationships. The results highlighted the diurnal variation in the photosynthetic rate and the heterosis effects on photosynthesis under different light intensities and $\mathrm{CO}_{2}$ concentrations. The purposes of this study were to explore the heterosis effects on photosynthesis in upland cotton leaves and their relationship with the environment and to provide a basis for the selection of improved photosynthesis of cotton varieties.

\section{Materials and methods}

Plant material and experimental site: Two cotton (Gossypium hirsutum L.) cultivars and their parents were used in this study. The test materials included Siza 3 and its female parent (Siyang 211) and male parent (Siyang 280) as well as Zhongmiansuo 48 and its female parent (971300) and male parent (951188). The experiment was carried out at the Liuhe Experimental Station in Nanjing, Jiangsu, China. The seedlings were transplanted from a nutrient bowl (paper cup); the sowing date was 6 April 2012. The seedlings were film-transplanted on 6 May. Each material was planted in six rows, with a plant spacing of $30 \mathrm{~cm}$. There were wide and narrow planting rows: the narrow row spacing was $50 \mathrm{~cm}$, while the wide row spacing was $120 \mathrm{~cm}$; the average row spacing was $85 \mathrm{~cm}$. The soil type of the plots was a sandy loam. The basal fertilizer comprised a compound fertilizer $(\mathrm{N}: \mathrm{P}: \mathrm{K}=1: 1: 1)$ applied at $450 \mathrm{~kg} \mathrm{ha}^{-1}$ together with a compound microbial fertilizer applied at $2,250 \mathrm{~kg} \mathrm{ha}^{-1}$. For topdressing, $\mathrm{KCl}$ was applied at $225 \mathrm{~kg} \mathrm{ha}^{-1}$, compound fertilizer $(\mathrm{N}: \mathrm{P}: \mathrm{K}=$ $1: 1: 1)$ was applied at $150 \mathrm{~kg} \mathrm{ha}^{-1}$, and urea was applied at $300 \mathrm{~kg} \mathrm{ha}^{-1}$. Other cultural practices were consistent with conventional cultivation management practices in the field. Cotton growth conditions were recorded during measurements. During the boll opening stage, functional leaves of the main stem of the cotton plants were measured.

Diurnal variation in the photosynthetic rate: In 2012 , an LI-6400 portable photosynthesis system analyzer (LI-COR, Inc., Lincoln, Nebraska, USA) was used to measure the gas-exchange parameters of the main stem functional leaves (each fourth leaf from the top) in Nanjing. Four plants were randomly selected for each material, and their leaves were marked for measurement. Measurements were performed every $2 \mathrm{~h}$ from 6:00-18:00 h. Each measurement was repeated three times under the same conditions [irradiance of $200 \mu \mathrm{mol}$ (photon) $\mathrm{m}^{-2} \mathrm{~s}^{-1}$; temperature of $26.7^{\circ} \mathrm{C}$; relative humidity of $70.3 \%$; and vapor pressure deficit of $1.03 \mathrm{kPa}$.

Light-response and $\mathbf{C O}_{2}$-response curve: In 2012, three typical Siza 3 plants and their parents and three typical Zhongmiansuo 48 plants and their parents were randomly selected in Nanjing. The $L I-6400$ portable photosynthesis system analyzer (LI-COR, Inc., Lincoln, Nebraska, USA) was used to measure the photosynthesis parameters of the functional leaves (each fourth leaf from the top) of the main stems The light-response curves were measured under PPFD of $0,50,100,150,200,250,500,800 ; 1,000$; 1,$200 ; 1,500 ; 1,800 ;$ and $2,000 \mu \mathrm{mol}$ (photon) $\mathrm{m}^{-2} \mathrm{~s}^{-1}$. The $\mathrm{CO}_{2}$-response curves were measured at the $\mathrm{CO}_{2}$ concentration of $0,50,75,100,150,200,250,300,400$, 600,$800 ; 1,000 ; 1,200 ; 1,400 ; 1,600 ; 1,800 ;$ and 2,000 $\mu \mathrm{mol} \mathrm{mol}{ }^{-1}$ (temperature of $26.7^{\circ} \mathrm{C}$, relative humidity of $70.3 \%$, and vapor pressure deficit of $1.03 \mathrm{kPa}$ ).

Chl fluorescence kinetic parameters: In 2012, during the flocking season in the field at Nanjing, three typical Siza 3 plants and their parents and three typical Zhongmiansuo 48 plants and their parents were removed at 10:00, 12:00, and 14:00 h on sunny days, wetted, and then placed in a dark room for dark adaptation for 15-20 min. Chl fluorescence parameters were subsequently measured with actinic light intensity of 1,500 $\mu \mathrm{mol}$ (photon) $\mathrm{m}^{-2} \mathrm{~s}^{-1}$ using a plant efficiency analyzer (Handy PEA, Hansatech, UK).

Statistical analysis: Data analysis and plotting were performed using Excel $X P$ and Origin 8.5 software. SPSS 19.0 was used to calculate the correlations between photosynthesis-related parameters and Chl fluorescence parameters.

Light-response curve: Cotton leaves were measured at various photosynthetic photon flux densities (PPFDs). A $P_{\mathrm{N}}$ response model was created, and Origin 8.5 data processing software was used to fit the data (Ye and Yu 
2007). The following equation was used:

$P_{\mathrm{N}}=\alpha \frac{1-\beta I}{1+\gamma I} I-R_{\mathrm{D}}$

where $\alpha$ is the initial slope of the light-response curve (dimensionless), $\beta$ and $\gamma$ are coefficients, $P_{\mathrm{N}}$ is the net photosynthetic rate, $I$ is the photosynthetically active radiation, and $R_{\mathrm{D}}$ is the dark respiration rate.

$\mathrm{CO}_{2}$-response curve: The $\mathrm{CO}_{2}$-response curve of cotton leaves under the saturated light intensity was fitted using a photosynthesis $\mathrm{CO}_{2}$-response model and Origin 8.5 data processing software ( $\mathrm{Ye}$ and $\mathrm{Yu}$ 2009). The following equation was used:

$P_{\mathrm{N}}=\mathrm{a} \frac{1-\mathrm{b} C_{\mathrm{i}}}{1+\mathrm{c} C_{\mathrm{i}}} C_{\mathrm{i}}-R_{\mathrm{P}}$

where $\mathrm{a}$ is the initial carboxylation efficiency of the $\mathrm{CO}_{2}$-response curve, $\mathrm{b}$ and $\mathrm{c}$ are coefficients $\left[\mathrm{mol} \mu \mathrm{mol}^{-1}\right]$, $P_{\mathrm{N}}$ is the net photosynthetic rate, $C_{\mathrm{i}}$ is the intercellular $\mathrm{CO}_{2}$ concentration, and $R_{\mathrm{P}}$ is the photorespiration rate.

Over better-parent heterosis $(\mathbf{O H})$ : The $\mathrm{OH}$ was calculated as: $\mathrm{OH}[\%]=\left[\mathrm{F}_{1}-\right.$ better (male parent, female parent)]/better (male parent, female parent) $\times 100$.

\section{Results}

Net photosynthetic rate: The $P_{\mathrm{N}}$ of Zhongmiansuo 48 and its parents exhibited double-peak curves, which were the highest at 10:00 h; thereafter they decreased substantially at 12:00 h, increased slightly at 14:00 h, and then decreased substantially again. The $P_{\mathrm{N}}$ of Zhongmiansuo 48 was slightly higher than that of its female parent, and there was no obvious $\mathrm{OH}$; moreover, the $P_{\mathrm{N}}$ was significantly higher than that of the male parent (Fig. 1A). The diurnal variation in the $P_{\mathrm{N}}$ of Siza 3 and its female parent exhibited a double-peak curve, which was the highest at 10:00 h; then it decreased substantially at $12: 00 \mathrm{~h}$, increased slightly at 14:00 h, and then decreased substantially again. The $P_{\mathrm{N}}$ of the male parent exhibited a unimodal curve. From 10:00 to 12:00 h, the $P_{\mathrm{N}}$ of Siza 3 was higher than that of its parent, and its $\mathrm{OH}$ was obvious (Fig. $1 B$ ). The male parent of Siza 3 did not present a decrease in the $P_{\mathrm{N}}$ under stress and it was less affected by the environment. The $\mathrm{OH}$ of the $P_{\mathrm{N}}$ of Siza 3 was more obvious than that of Zhongmiansuo 48.

Stomatal conductance: At 10:00 and 14:00 h, there was no significant difference in $g_{\mathrm{s}}$ between Zhongmiansuo 48 and its female parent, but it was higher than that of the male parent. In addition, there was no significant difference in $g_{\mathrm{s}}$ at 12:00 h (Fig. 1C). The daily variation in $g_{\mathrm{s}}$ of Siza 3 and

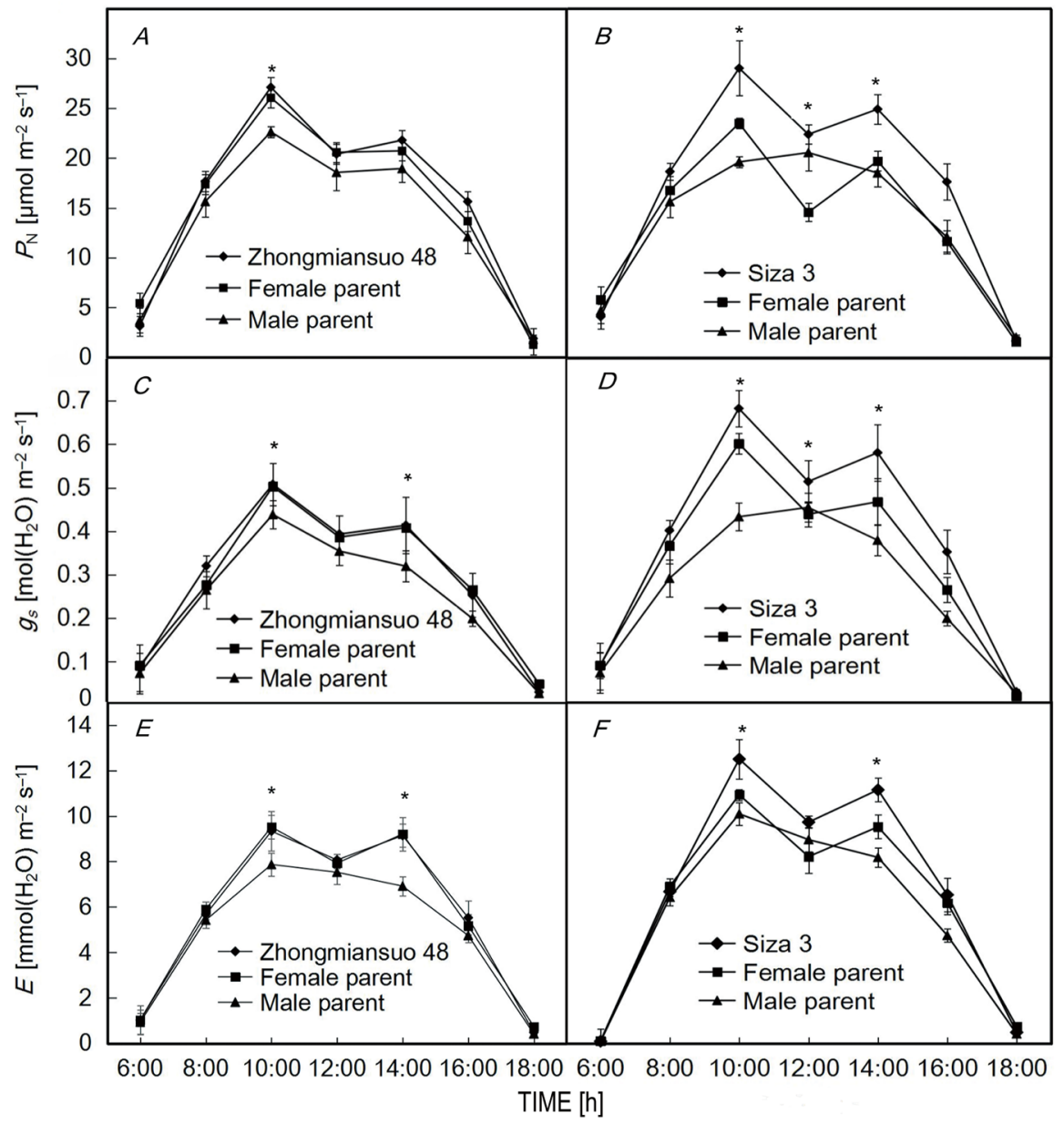

Fig. 1. Diurnal changes in gasexchange parameters of Zhongmiansuo 48, Siza 3, and their parents. Net photosynthetic rate $\left(P_{\mathrm{N}}\right)$ of Zhongmiansuo 48 and its parents $(A)$ and Siza 3 and its parents $(B)$. Stomatal conductance $\left(g_{s}\right)$ of Zhongmiansuo 48 and its parents $(C)$ and Siza 3 and its parents $(D)$. Transpiration rate $(E)$ of Zhongmiansuo 48 and its parents $(E)$ and Siza 3 and its parents $(F)$. Values are means $\pm \mathrm{SD}, n=3$. *The difference is significant at the 0.05 level. 
its female parent exhibited a double-peak curve, while the daily variation in $g_{\mathrm{s}}$ of its male parent exhibited the singlepeak curve. The $g_{\mathrm{s}}$ of Siza 3 was higher than that of its parents at both 10:00 and 14:00 h (Fig. 1D). Moreover, the results showed that, compared with that of Zhongmiansuo 48 , the $\mathrm{OH}$ of Siza 3 in terms of $g_{\text {s }}$ was more obvious. Overall, the daily trend of $g_{\mathrm{s}}$ was essentially consistent with that of the $P_{\mathrm{N}}$.

Transpiration rate: The daily change in the $E$ of Zhongmiansuo 48 and its parents exhibited a double-peak curve. Their $E$ peaked at 10:00 h. There was no significant difference in $E$ between Zhongmiansuo 48 and its female parent, but it was higher than that of the male parent. At 12:00 h, the $E$ of Zhongmiansuo 48 was higher than that of its parent (Fig. $1 E$ ). The daily variation in the $E$ of Siza 3 and its female parent exhibited a double-peak curve, while the $E$ of its male parent exhibited a single-peak curve. The $E$ of Siza 3 and its parents peaked at approximately 10:00 h, and the $E$ of Siza 3 and its female parents did not significantly differ (Fig. $1 F$ ). The $E$ of Zhongmiansuo 48 and Siza 3 were higher than those of their male parents but were not significantly different from those of their female parent.

Diurnal changes in the $\mathrm{OH}$ of photosynthesis: The $P_{\mathrm{N}}$, $g_{\text {s }}$, and $E$ of Zhongmiansuo 48 and its parents did not demonstrate obvious $\mathrm{OH}$ (Fig. 2). However, the $P_{\mathrm{N}}, g_{\mathrm{s}}$, and $E$ of Siza 3 and its parents showed a clear OH. At approximately $16: 00 \mathrm{~h}$, the $\mathrm{OH}$ of the $P_{\mathrm{N}}$ and $g_{\text {s }}$ peaked, which were 45.7 and $33.0 \%$ of Siza 3, respectively. At approximately $14: 00 \mathrm{~h}$, the $\mathrm{OH}$ of the $E$ was $17.1 \%$, which was the highest value of the day. These results show that this cultivar displayed obvious $\mathrm{OH}$ under conditions of high temperature and high light, and the $\mathrm{OH}$ was very obvious between 14:00-16:00 h (Fig. 2).

Diurnal variation of environmental factors: At 10:00 h [air temperature $\left(\mathrm{T}_{\text {air }}\right)$ of $35.1^{\circ} \mathrm{C}$; relative humidity $(\mathrm{RH})$ of $56.5 \%$; vapor pressure deficit (VPD) of $2.03 \mathrm{kPa}$, the $P_{\mathrm{N}}, g_{\mathrm{s}}$, and $E$ of each variety were the highest, indicating that the environment at that time was more suitable for photosynthesis of these six upland cotton varieties and their $\mathrm{F}_{1}$ hybrid progeny. At $12: 00 \mathrm{~h}\left[\mathrm{~T}_{\text {air }}\right.$ of $37.3^{\circ} \mathrm{C} ; \mathrm{RH}$ of $48.3 \%$; VPD of $2.29 \mathrm{kPa}$; PPFD of $2,035 \mu \mathrm{mol} \mathrm{m} \mathrm{m}^{-2} \mathrm{~s}^{-1}$ ] (Fig. 3), the parameters of the $P_{\mathrm{N}}, g_{\mathrm{s}}$, and $E$ of the five varieties (lines), Zhongmiansuo 48 and its parents as well as Siza 3 and its female parent, were lower than those at 10:00 $\mathrm{h}$. These results show that the environment at noon had an adverse effect on photosynthesis. At 14:00 h, although the maximum temperature reached $37.9^{\circ} \mathrm{C}$, it was higher than that at 12:00 h. However, the photosynthesis of each variety (line) increased significantly compared to that at 12:00. This may be related to the increase in light intensity, RH, and VPD.

Correlations between photosynthesis parameters and environmental factors: Photosynthesis parameters are closely related to the environment. The $P_{\mathrm{N}}, g_{\mathrm{s}}$, and $E$ of Zhongmiansuo 48 and its parents and Siza 3 and its male parent were extremely significantly positively correlated with PPFD (Table 1). The $P_{\mathrm{N}}, g_{\mathrm{s}}$, and $E$ of Zhongmiansuo 48 and Siza 3 and their respective parents were positively correlated with VPD. Furthermore, the $P_{\mathrm{N}}, g_{\mathrm{s}}$, and $E$ of Zhongmiansuo 48 and its parents and Siza 3 and its male parent were significantly positively correlated with $\mathrm{T}_{\text {air. }}$ However, the $P_{\mathrm{N}}, g_{\mathrm{s}}$, and $E$ of Zhongmiansuo 48 and Siza 3 and their respective parents were negatively correlated with RH. Taken together, these results show that high PPFD and $\mathrm{T}_{\text {air }}$ are beneficial for photosynthesis and that high RH is not beneficial for photosynthesis.

The light-response curve and $\mathbf{O H}$ : The higher the light intensity was, the higher the $P_{\mathrm{N}}$ of each plant variety was. Under low-light intensities, the photosynthetic rate of the different varieties was not significantly different. The higher the light intensity, the more obvious the difference in photosynthetic rate between the different varieties. The

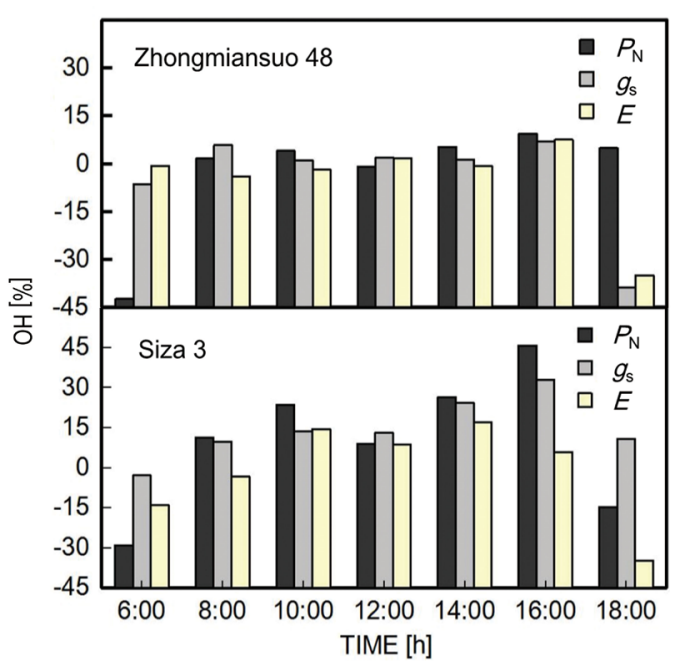

Fig. 2. Diurnal variations of the trend of the over better-parent heterosis $(\mathrm{OH})$ in two cotton cultivars. $E$ - transpiration rate; $g_{\mathrm{s}}-$ stomatal conductance; $P_{\mathrm{N}}-$ net photosynthesis rate.

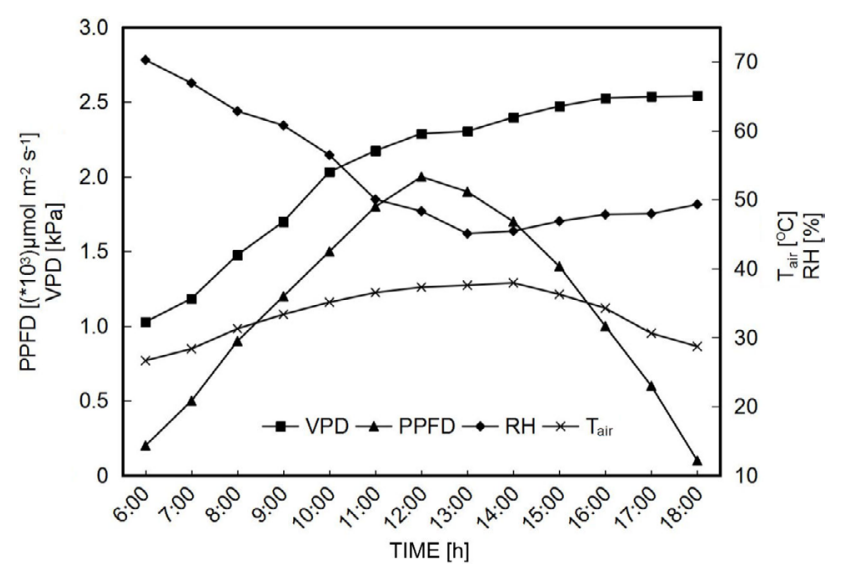

Fig. 3. Diurnal variation of environmental factors. PPFD photosynthetic photon flux density; VPD - vapor pressure deficit; $\mathrm{T}_{\text {air }}$ - air temperature; $\mathrm{RH}$ - relative humidity. 
light-saturation points $\left(\mathrm{I}_{\mathrm{m}}\right)$ of the different parents and $\mathrm{F}_{1}$ hybrids were significantly different. Siza 3 had the highest $\mathrm{I}_{\mathrm{m}}$, and its male parent had the lowest $\mathrm{I}_{\mathrm{m}}$. When the light intensity was lower than $500 \mu \mathrm{mol}$ (photon) $\mathrm{m}^{-2} \mathrm{~s}^{-1}$, the $P_{\mathrm{N}}$ of Zhongmiansuo 48 and its parents were essentially the same. When the light intensity was higher than 500 $\mu$ mol(photon) $\mathrm{m}^{-2} \mathrm{~s}^{-1}$, the difference between the $P_{\mathrm{N}}$ of Zhongmiansuo 48 and that of its parents increased. Zhongmiansuo 48 demonstrated the highest $P_{\mathrm{N}}$, followed by its female parent, whereas the male parent presented the lowest $P_{\mathrm{N}}$. However, the increase in the $P_{\mathrm{N}}$ was not significant. The apparent quantum efficiency, $\mathrm{I}_{\mathrm{m}}$, light-saturated net photosynthetic rate $\left(P_{\mathrm{Nmax}}\right)$, lightcompensation point $\left(\mathrm{I}_{\mathrm{c}}\right)$, and $R_{\mathrm{D}}$ of Zhongmiansuo 48 were higher than those of its parents, but there was no obvious $\mathrm{OH}$. When the light intensity was lower than $250 \mu \mathrm{mol}$ (photon) $\mathrm{m}^{-2} \mathrm{~s}^{-1}$, the $P_{\mathrm{N}}$ of Siza 3 and its parents was essentially the same. When the light intensity was higher than $500 \mu \mathrm{mol}$ (photon) $\mathrm{m}^{-2} \mathrm{~s}^{-1}$, the $P_{\mathrm{N}}$ significantly differed between Siza 3 and its parents. Siza 3 had the highest $P_{\mathrm{N}}$, followed by its female parent, and the male parent had the lowest $P_{\mathrm{N}}$. Siza 3 displayed obvious heterosis. As the light intensity increased, the $\mathrm{OH}$ increased. When the light intensity reached 1,500 $\mu$ mol(photon) $\mathrm{m}^{-2} \mathrm{~s}^{-1}$, the $\mathrm{OH}$ peaked by $33.3 \%$. These results show that the photosynthesis of this hybrid is related to light intensity. The higher the light intensity, the stronger the heterosis (Fig. 4, Table 2). The $\mathrm{OH}$ of Siza 3 was obvious, and the $\mathrm{OH}$ of apparent quantum efficiency and the $P_{\text {Nmax }}$ were 34.7 and $18.6 \%$, respectively, for this variety. However, the $\mathrm{I}_{\mathrm{c}}$ displayed a negative $\mathrm{OH}(-18.5 \%)$. When the light intensity exceeded $1,500 \mu \mathrm{mol}$ (photon) $\mathrm{m}^{-2} \mathrm{~s}^{-1}$, the $P_{\mathrm{N}}$ of each variety did not increase significantly.

The apparent quantum efficiency, $\mathrm{I}_{\mathrm{m}}$, and $P_{\mathrm{Nmax}}$ of Zhongmiansuo 48 were lower than those of Siza 3, indicating that photosynthesis of Siza 3 is more efficient than that of Zhongmiansuo 48 under different light intensities (Fig. 4). The $I_{c}$ of Zhongmiansuo 48 was higher than that of Siza 3, indicating that the ability to use weak light is lower in the former than in Siza 3. Furthermore, the dark respiration rate of Zhongmiansuo 48 was essentially the same as that of Siza 3.

The effects and OH of different PPFDs on $g_{s}$ of two hybrids: Under different light intensities, the $g_{\mathrm{s}}$ of the male parent of Zhongmiansuo 48 was higher than that of Zhongmiansuo 48 and its female parent, and there was no heterosis. The $g_{\mathrm{s}}$ of Siza 3 and its parents increased with increasing light intensity. When the light intensity was lower than $300 \mu \mathrm{mol}$ (photon) $\mathrm{m}^{-2} \mathrm{~s}^{-1}$, there was no significant difference in $g_{\mathrm{s}}$ between the three varieties. However, when the light intensity was higher than $300 \mu \mathrm{mol}$ (photon) $\mathrm{m}^{-2} \mathrm{~s}^{-1}$, the $g_{\mathrm{s}}$ of Siza 3 was higher than that of its parent, and it presented a very significant $\mathrm{OH}$. The $\mathrm{OH}$ gradually increased with increasing light intensity. When the light intensity reached 2,000 $\mu$ mol(photon) $\mathrm{m}^{-2} \mathrm{~s}^{-1}$, the $\mathrm{OH}$ peaked $(20.2 \%)$. This shows that with increasing light intensity, the $\mathrm{OH}$ of the $g_{\mathrm{s}}$ of Siza 3 also gradually increased. The higher the light intensity, the more obvious the $\mathrm{OH}$ (Fig. 5).

$\mathrm{CO}_{2}$-response curve and $\mathrm{OH}$ : The higher the $\mathrm{CO}_{2}$ concentration was, the higher the $P_{\mathrm{N}}$ of each plant variety was. When the $\mathrm{CO}_{2}$ concentration was higher than 900

Table 1. Correlations between photosynthesis parameters of the different cotton varieties and environmental factors. *Correlation is significant at the 0.05 level. ${ }^{*}$ Correlation is significant at the 0.01 level. $E$ - transpiration rate; $g_{\mathrm{s}}-$ stomatal conductance; $P_{\mathrm{N}}-$ net photosynthetic rate; PPFD - photosynthetic photon flux density; RH - relative humidity; $\mathrm{T}_{\text {air }}$ - air temperature; VPD - vapor pressure deficit.

\begin{tabular}{llllll}
\hline & & PPFD & VPD & $\mathrm{T}_{\text {air }}$ & RH \\
\hline$P_{\mathrm{N}}$ & Siza 3 & $0.907^{* *}$ & 0.246 & $0.877^{* *}$ & -0.342 \\
& Female parent & $0.805^{*}$ & 0.055 & 0.75 & -0.148 \\
& Male parent & $0.956^{* *}$ & 0.187 & $0.882^{* *}$ & -0.316 \\
Zhongmiansuo 48 & $0.894^{* *}$ & 0.240 & $0.859^{*}$ & -0.326 \\
& Female parent & $0.899^{* *}$ & 0.135 & $0.829^{*}$ & -0.234 \\
& Male parent & $0.914^{* *}$ & 0.192 & $0.857^{*}$ & -0.294 \\
$g_{\text {s }}$ & Siza 3 & $0.915^{* *}$ & 0.231 & $0.875^{* *}$ & -0.330 \\
& Female parent & $0.889^{* *}$ & 0.152 & $0.825^{*}$ & -0.246 \\
& Male parent & $0.965^{* *}$ & 0.205 & $0.878^{* *}$ & -0.329 \\
& Zhongmiansuo 48 & $0.901^{* *}$ & 0.168 & $0.840^{*}$ & -0.264 \\
& Female parent & $0.919^{* *}$ & 0.249 & $0.877^{* *}$ & -0.341 \\
Male parent & $0.901^{* *}$ & 0.163 & $0.824^{*}$ & -0.251 \\
$E$ & Siza 3 & $0.928^{* *}$ & 0.339 & $0.914^{* *}$ & -0.434 \\
& Female parent & $0.902^{* *}$ & 0.321 & $0.892^{* *}$ & -0.409 \\
& Male parent & $0.936^{* *}$ & 0.273 & $0.884^{* *}$ & -0.371 \\
Zhongmiansuo 48 & $0.947^{* *}$ & 0.303 & $0.925^{* *}$ & -0.417 \\
& Female parent & $0.936^{* *}$ & 0.290 & $0.911^{* *}$ & -0.402 \\
Male parent & $0.954^{* *}$ & 0.259 & $0.902^{* *}$ & -0.369 \\
\hline
\end{tabular}


$\mu \mathrm{mol} \mathrm{mol} \mathrm{m}^{-1}$, the $P_{\mathrm{N}}$ of Zhongmiansuo 48 displayed no obvious $\mathrm{OH}$. When the $\mathrm{CO}_{2}$ concentration was lower than $750 \mu \mathrm{mol} \mathrm{mol}{ }^{-1}$, the $P_{\mathrm{N}}$ of Zhongmiansuo 48 was higher than that of its parents, but the differences were not significant. The intercellular $\mathrm{CO}_{2}$ concentration $\left(C_{\mathrm{i}}\right)$, $P_{\mathrm{Nmax}}, \mathrm{CO}_{2}$-compensation point $(\Gamma)$, and $R_{\mathrm{P}}$ of Zhongmiansuo 48 displayed negative $\mathrm{OH}$, and the $\mathrm{OH}$ of initial carboxylation efficiency reached only 9.3\% (Fig. 6; Table 1S, supplement). At saturated light intensity, the higher the $\mathrm{CO}_{2}$ concentration, the more obvious the $\mathrm{OH}$ of the $P_{\mathrm{N}}$ of Siza 3. The initial carboxylation efficiency of Siza 3 was significantly higher than that of its parent, and its $\mathrm{OH}$ was obvious. The $\mathrm{CO}_{2}$-concentration saturation point of Siza 3 exhibited no obvious $\mathrm{OH}$, and the $\Gamma$ point and $R_{\mathrm{P}}$ were significantly lower than those of its parents, which resulted in a negative $\mathrm{OH}$ (Fig. 6, Table 1S). In the $\mathrm{CO}_{2}$-response curve, the $\mathrm{OH}$ of the initial carboxylation efficiency and the maximum $P_{\mathrm{N}}$ of Siza 3 were 26.0 and $16.6 \%$, respectively, which were higher than those of Zhongmiansuo 48 . The $C_{\mathrm{i}}, \Gamma$, and $R_{\mathrm{P}}$ of Siza 3 displayed negative $\mathrm{OH}$, which was essentially the same as that of Zhongmiansuo 48 . The $\Gamma$ and $R_{\mathrm{P}}$ of Zhongmiansuo 48 and Siza 3 displayed negative $\mathrm{OH}$, indicating that, compared to their parents, these two hybrids had lower $\Gamma$ and photorespiration rates at relatively low $\mathrm{CO}_{2}$ concentrations and displayed heterosis effects.
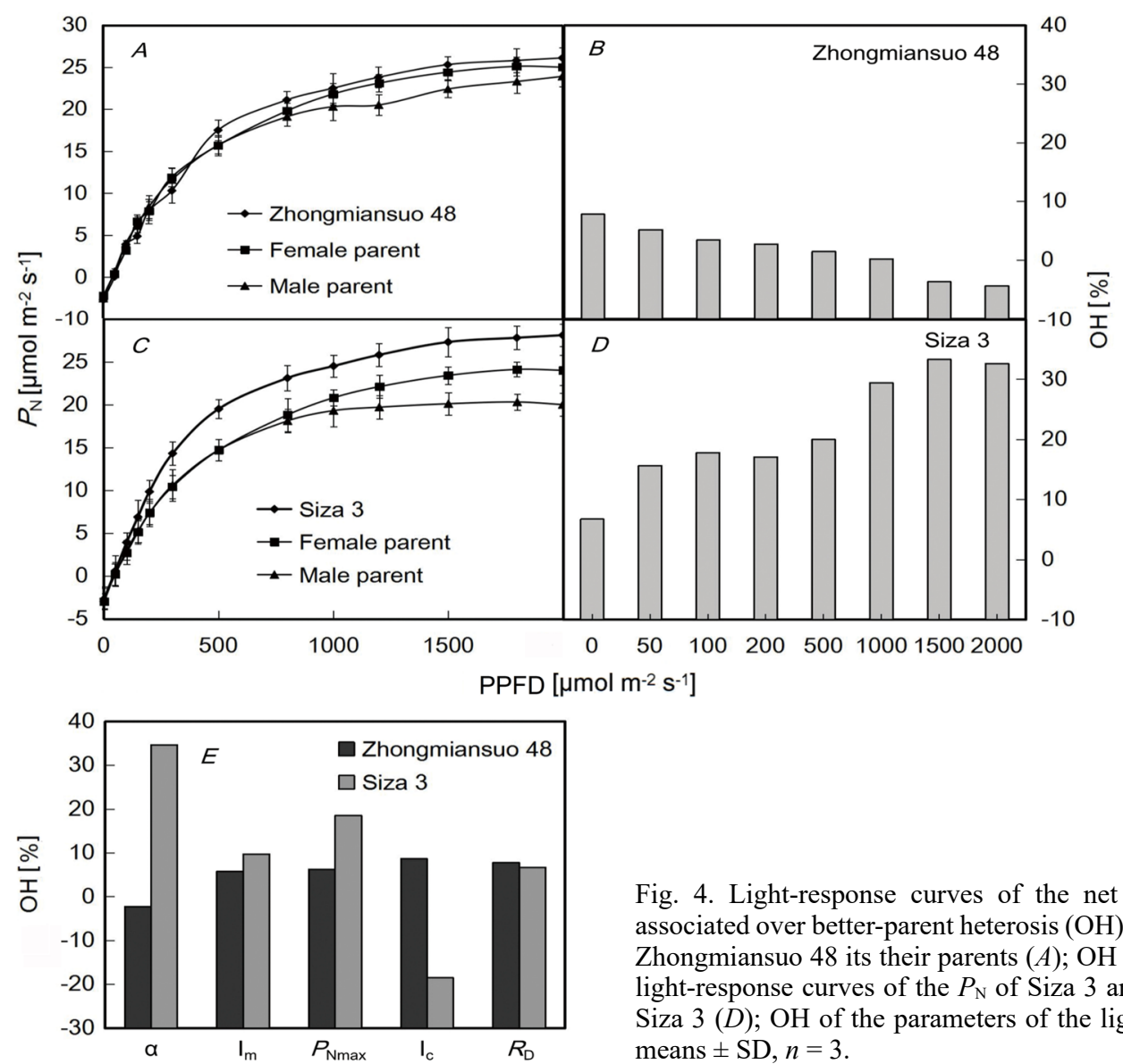

Fig. 4. Light-response curves of the net photosynthetic rate $\left(P_{\mathrm{N}}\right)$ and the associated over better-parent heterosis $(\mathrm{OH})$. Light-response curves of the $P_{\mathrm{N}}$ of Zhongmiansuo 48 its their parents $(A)$; $\mathrm{OH}$ of the $P_{\mathrm{N}}$ of Zhongmiansuo $48(B)$; light-response curves of the $P_{\mathrm{N}}$ of Siza 3 and its parents $(C) ; \mathrm{OH}$ of the $P_{\mathrm{N}}$ of Siza $3(D)$; $\mathrm{OH}$ of the parameters of the light-response curves $(E)$. Values are means $\pm \mathrm{SD}, n=3$.

Table 2. Parameters of the light-response curves. A - apparent quantum yield; $\mathrm{I}_{\mathrm{m}}-$ light-saturation point; $P_{\mathrm{Nmax}}-$ maximum net photosynthetic rate; $\mathrm{I}_{\mathrm{c}}$ - light-compensation point; $R_{\mathrm{D}}$ - dark respiration rate. Values are means $\pm \mathrm{SD}(n=3)$. Different lowercase letters denote significant differences at $P \leq 0.05$.

\begin{tabular}{llllll}
\hline Cultivar & $\alpha$ & $\begin{array}{l}\mathrm{I}_{\mathrm{m}} \\
{\left[\mu \mathrm{mol} \mathrm{m} \mathrm{s}^{-1}\right]}\end{array}$ & $\begin{array}{l}P_{\mathrm{Nmax}} \\
{\left[\mu \mathrm{mol} \mathrm{m}{ }^{-2} \mathrm{~s}^{-1}\right]}\end{array}$ & $\begin{array}{l}\mathrm{I}_{\mathrm{c}} \\
{\left[\mu \mathrm{mol} \mathrm{m}^{-2} \mathrm{~s}^{-1}\right]}\end{array}$ & $\begin{array}{l}R_{\mathrm{D}} \\
{\left[\mu \mathrm{mol} \mathrm{m}^{-2} \mathrm{~s}^{-1}\right]}\end{array}$ \\
\hline Zhongmiansuo 48 & $0.0701 \pm 0.0043^{\mathrm{a}}$ & $2,072.8 \pm 34.3^{\mathrm{a}}$ & $25.97 \pm 2.35^{\mathrm{a}}$ & $44.94 \pm 2.35^{\mathrm{a}}$ & $2.94 \pm 0.17^{\mathrm{a}}$ \\
Female parent & $0.0717 \pm 0.0034^{\mathrm{a}}$ & $1,958.7 \pm 52.3^{\mathrm{a}}$ & $24.25 \pm 2.95^{\mathrm{a}}$ & $37.66 \pm 2.46^{\mathrm{a}}$ & $2.53 \pm 0.14^{\mathrm{a}}$ \\
Male parent & $0.0779 \pm 0.0045^{\mathrm{a}}$ & $1,883.4 \pm 56.7^{\mathrm{a}}$ & $21.95 \pm 2.18^{\mathrm{a}}$ & $36.76 \pm 2.24^{\mathrm{a}}$ & $2.79 \pm 0.17^{\mathrm{a}}$ \\
Siza 3 & $0.0964 \pm 0.0035^{\mathrm{a}}$ & $2,290.7 \pm 40.9^{\mathrm{a}}$ & $28.06 \pm 2.19^{\mathrm{a}}$ & $38.75 \pm 2.47^{\mathrm{b}}$ & $3.43 \pm 0.13^{\mathrm{a}}$ \\
Female parent & $0.0667 \pm 0.0030^{\mathrm{b}}$ & $2,086.9 \pm 62.8^{\mathrm{b}}$ & $23.67 \pm 2.25^{\mathrm{b}}$ & $47.55 \pm 2.39^{\mathrm{a}}$ & $2.94 \pm 0.17^{\mathrm{b}}$ \\
Male parent & $0.0715 \pm 0.0045^{\mathrm{b}}$ & $1,575.9 \pm 46.9^{\mathrm{c}}$ & $20.30 \pm 1.83^{\mathrm{b}}$ & $43.82 \pm 2.52^{\mathrm{a}}$ & $2.89 \pm 0.24^{\mathrm{b}}$ \\
\hline
\end{tabular}




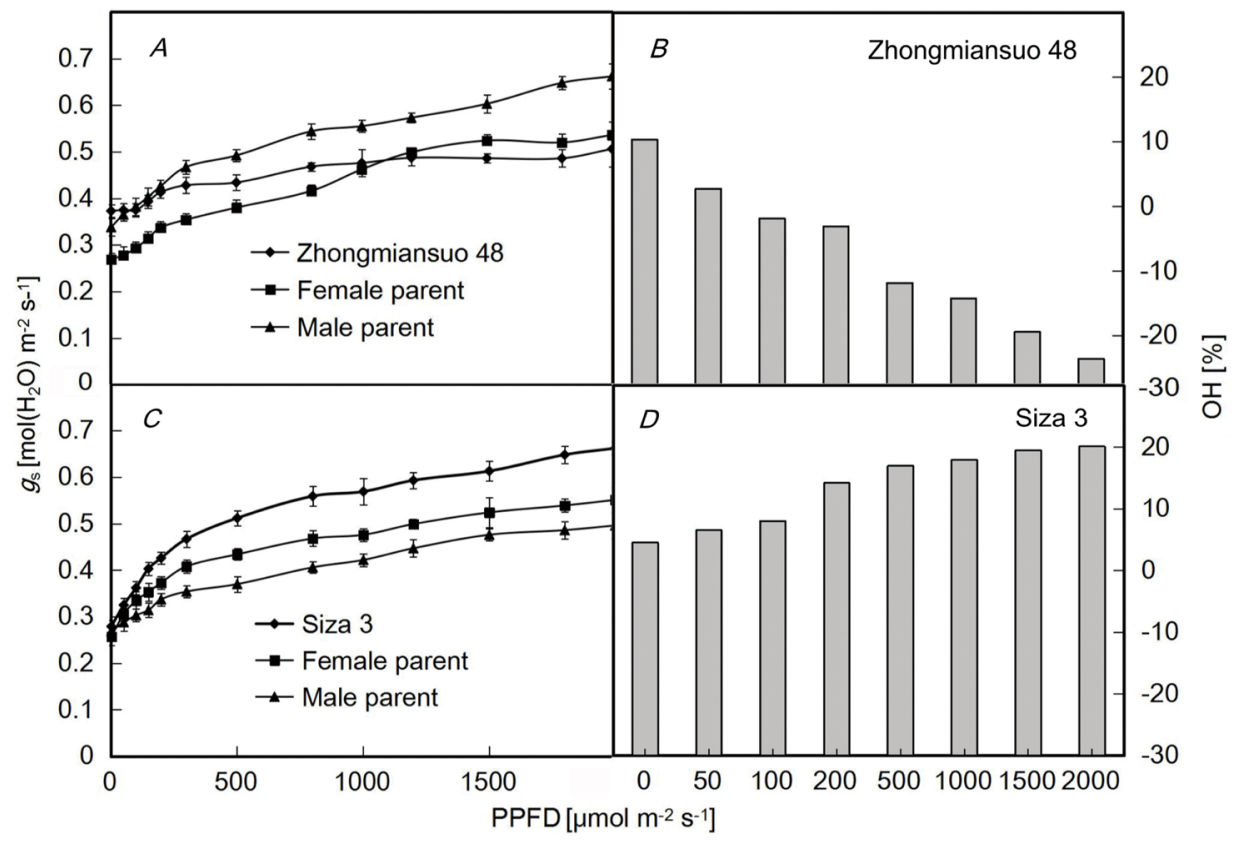

Fig. 5. Light-response curves of stomatal conductance $\left(g_{\mathrm{s}}\right)$ and the associated over better-parent heterosis $(\mathrm{OH})$. Light-response curves of the $g_{\mathrm{s}}$ of Zhongmiansuo 48 and its parents $(A) ; \mathrm{OH}$ of the $g_{\mathrm{s}}$ of Zhongmiansuo $48(B)$; light-response curves of the $g_{\mathrm{s}}$ of Siza 3 and its parents $(C)$; $\mathrm{OH}$ of the $g_{\mathrm{s}}$ of Siza $3(D)$. Values are means $\pm \mathrm{SD}, n=3$.
$\mathrm{CO}_{2}$-response curves of the $\mathrm{g}_{\mathrm{s}}$ and the associated $\mathrm{OH}$ : The higher the $\mathrm{CO}_{2}$ concentration, the lower the $g_{\mathrm{s}}$ of each variety. The $g_{\mathrm{s}}$ of Zhongmiansuo 48 and its parents increased when the $\mathrm{CO}_{2}$ concentration was lower than $200 \mu \mathrm{mol} \mathrm{mol}{ }^{-1}$. However, when the $\mathrm{CO}_{2}$ concentration was higher than $200 \mu \mathrm{mol} \mathrm{mol}{ }^{-1}$, the $g_{\mathrm{s}}$ decreased. The change in $g_{\mathrm{s}}$ of Siza 3 and its parents was similar to that of Zhongmiansuo 48. There was no significant difference in $g_{s}$ between Zhongmiansuo 48 and its parents under different $\mathrm{CO}_{2}$ concentrations (Fig. 1S, supplement). When the $\mathrm{CO}_{2}$ concentration was higher than $200 \mu \mathrm{mol} \mathrm{mol}{ }^{-1}$, the $g_{\mathrm{s}}$ of Siza 3 was not significantly different from that of its male parent but was higher than that of its female parent. The higher the $\mathrm{CO}_{2}$ concentration, the greater the $\mathrm{OH}$ of the $g_{\mathrm{s}}$ of Siza 3 (Fig. 1S).

Changes in the $\mathbf{F}_{\mathbf{0}}$ and $\mathrm{OH}$ : Original fluorescence $\left(\mathrm{F}_{0}\right)$ is a measure of the fluorescence intensity when the PSII reaction centers of the dark-adapted photosynthetic apparatus are fully opened. The increase in thermal dissipation of the PSII antenna leads to a decrease in $\mathrm{F}_{0}$, and the destruction or reversible inactivation of the PSII reaction center causes an increase in $\mathrm{F}_{0}$ (Biber 2012). The state of the reaction center can be inferred from changes in $\mathrm{F}_{0}$ (Georgieva and Yordanov 1993). At 10:00 h, there was no significant difference in $\mathrm{F}_{0}$ between Zhongmiansuo 48 and its parents. At 12:00 h, the $\mathrm{F}_{0}$ tended to increase from 10:00 h, and the $F_{0}$ of Zhongmiansuo 48 was lower than that of its parent. At 14:00 h, the $\mathrm{F}_{0}$ of the parents decreased slightly, and that of Zhongmiansuo 48 remained essentially unchanged. The $\mathrm{F}_{0}$ of Zhongmiansuo 48 at the three time points did not change significantly (Fig. 2SA, supplement). Moreover, at 10:00 h, the difference in $\mathrm{F}_{0}$ between Siza 3 and its parent was not significant. At 12:00 h, the $F_{0}$ of Siza 3 and its female parent increased significantly, but that of its male parent did not change significantly. At 14:00 h, the $F_{0}$ of Siza 3 and its female parent was lower than that at 12:00 $\mathrm{h}$, but the change in the Siza 3 male parent was not significant (Fig. 2S $B$ ). Together, these results show that the $\mathrm{F}_{0}$ of different varieties is not significantly different under nonstress conditions, that the $\mathrm{F}_{0}$ increases under stress conditions at 12:00 $\mathrm{h}$, and that there is a significant difference between varieties.

Changes in the $\mathbf{P I}_{\text {abs }}$ and $\mathbf{O H}$ : The $\mathrm{PI}_{\mathrm{abs}}$ is a photochemical performance index of PSII and accurately reflects the state of the plant photosynthetic apparatus. The $\mathrm{PI}_{\mathrm{abs}}$ is more sensitive to certain stresses than the maximal photochemical efficiency $\left(\mathrm{F}_{\mathrm{v}} / \mathrm{F}_{\mathrm{m}}\right)$ and reflects the impact of stress on the photosynthetic apparatus (Li et al. 2005). There was no significant difference in the $\mathrm{PI}_{a b s}$ between Zhongmiansuo 48 and its parents at 10:00 h. Moreover, at 12:00 h, the $\mathrm{PI}_{\text {abs }}$ of all three of these varieties declined. The $\mathrm{PI}_{\mathrm{abs}}$ of Zhongmiansuo 48 did not significantly differed compared with that of the Zhongmiansuo 48 female parent but was lower than that of the male parent, without obvious heterosis. At 14:00 h, the $\mathrm{PI}_{\text {abs }}$ of Zhongmiansuo 48 was higher than that of its parents (Fig. 2SC). There was no significant difference in $\mathrm{PI}_{\mathrm{abs}}$ between Siza 3 and its parents at 10:00 h. However, at 12:00 h, the $\mathrm{PI}_{\mathrm{abs}}$ of Siza 3 and its female parent decreased significantly, the $\mathrm{PI}_{\mathrm{abs}}$ of the female parent was lower than that of Siza 3, and the $\mathrm{PI}_{\mathrm{abs}}$ of the male parent decreased slightly. At 14:00 h, the $\mathrm{PI}_{\mathrm{abs}}$ of Siza 3 was higher than that of its parents (Fig. 2SD). The $\mathrm{PI}_{\mathrm{abs}}$ of Siza 3 was always higher than the values of Zhongmiansuo 48, indicating that Siza 3 has a higher electron transport ability. Overall, these results indicate that the $\mathrm{PI}_{\mathrm{abs}}$ of cotton leaves decreased under stress, and photosynthesis was essentially the same comparing the different varieties at 10:00 h. At 12:00 h, the $\mathrm{PI}_{\mathrm{abs}}$ of Siza 3 and Zhongmiansuo 48 displayed no $\mathrm{OH}$. At 14:00 h, they displayed the $\mathrm{OH}$, indicating that the leaf functions of the two hybrids recovered faster than did those of their parents after the stress was released. Under 

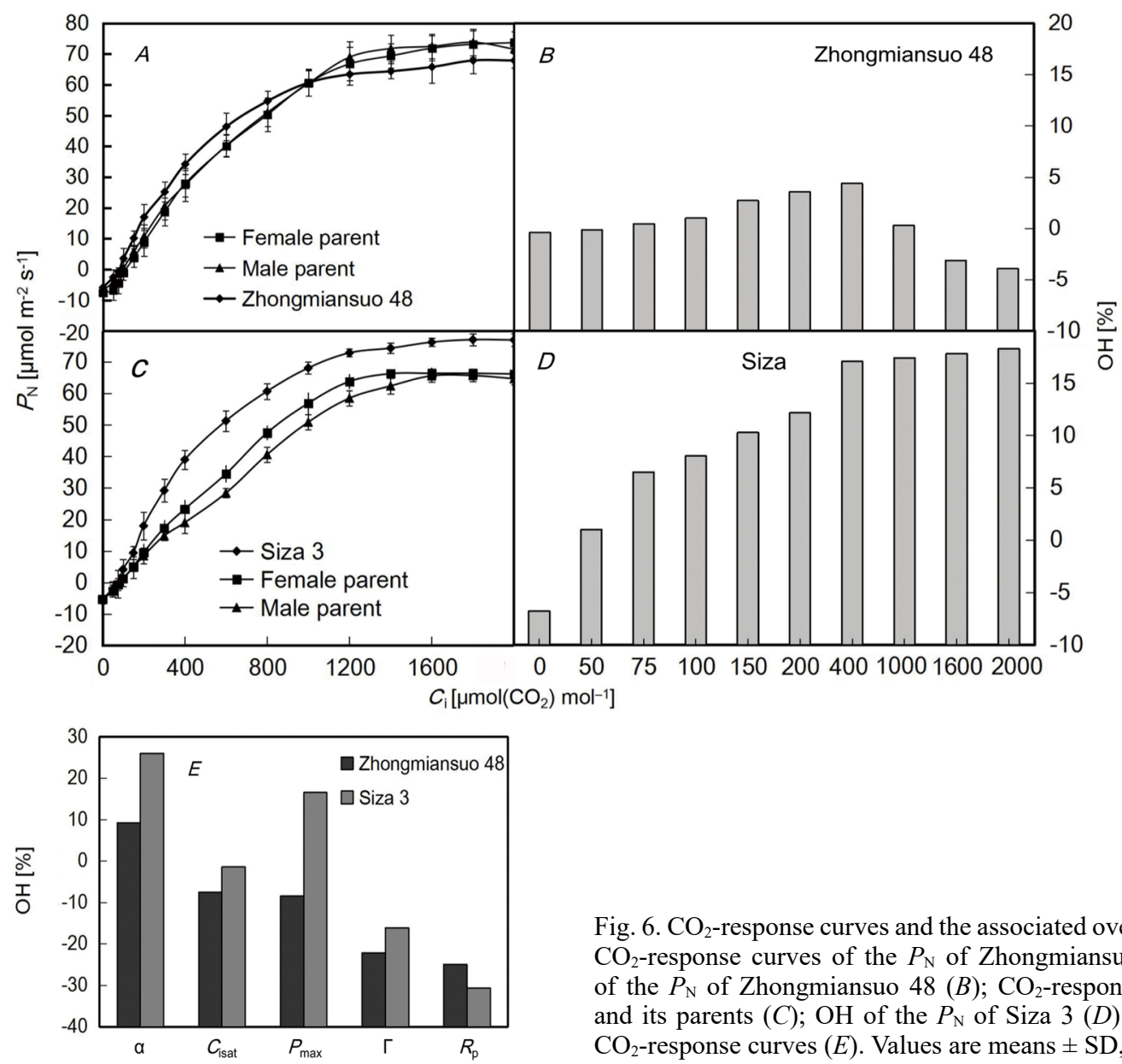

Fig. 6. $\mathrm{CO}_{2}$-response curves and the associated over better-parent heterosis $(\mathrm{OH})$. $\mathrm{CO}_{2}$-response curves of the $P_{\mathrm{N}}$ of Zhongmiansuo 48 and its parents $(A) ; \mathrm{OH}$ of the $P_{\mathrm{N}}$ of Zhongmiansuo $48(B) ; \mathrm{CO}_{2}$-response curves of the $P_{\mathrm{N}}$ of Siza 3 and its parents $(C)$; $\mathrm{OH}$ of the $P_{\mathrm{N}}$ of Siza $3(D)$; $\mathrm{OH}$ of the parameters of the $\mathrm{CO}_{2}$-response curves $(E)$. Values are means $\pm \mathrm{SD}, n=3$.

nonstress conditions, there was no significant difference in $\mathrm{PI}_{\mathrm{abs}}$ between the six varieties, but the differences in the $\mathrm{PI}_{\mathrm{abs}}$ between varieties could be identified under stress conditions.

Chl fluorescence intensity at the K-step $\left(V_{k}\right)$ and $\mathrm{OH}$ : Environmental stress leads to the emergence of the K-step on the $\mathrm{O}-\mathrm{J}-\mathrm{I}-\mathrm{P}$ curve. The $\mathrm{V}_{\mathrm{k}}$ can reflect the degree of damage of the oxygen-evolving complex (Li et al. 2005). At 10:00 h, the $V_{k}$ values of Zhongmiansuo 48 and its parents were not significantly different. At $12: 00 \mathrm{~h}$, the $\mathrm{V}_{\mathrm{k}}$ of the parents increased, and the $\mathrm{V}_{\mathrm{k}}$ of Zhongmiansuo 48 was lower than that of its parents. At 14:00 h, the $V_{k}$ of the parents slightly decreased, whereas that of Zhongmiansuo 48 remained essentially unchanged. The change in $V_{k}$ of Zhongmiansuo 48 at the three time points was not significant (Fig. 2SE). At 10:00 h, there was no significant difference in the $V_{k}$ between Siza 3 and its parents. However, at 12:00 h, the $V_{k}$ of Siza 3 and its female parent increased significantly, but the change in $V_{k}$ in the male parent was not significant. At 14:00 h, the $V_{k}$ of Siza 3 and its female parent began to decrease, but the change in $V_{k}$ in the male parent of Siza 3 was not significant (Fig. 2SF). Together, these results show that, under stress, the $\mathrm{V}_{\mathrm{k}}$ of the different varieties is essentially the same and that the $\mathrm{V}_{\mathrm{k}}$ of different varieties differs under stress conditions.

\section{Discussion}

Differences in photosynthesis parameters and OH: Due to different environments, the photosynthesis parameters of all varieties displayed obvious dynamic changes at different time points under different light intensities and $\mathrm{CO}_{2}$ concentrations during the day. The $P_{\mathrm{N}}$ of each variety was the highest at 10:00 h, indicating that various environmental parameters at this time were more suitable for photosynthesis of the leaves. Furthermore, the $P_{\mathrm{N}}$ was lower at 12:00 $\mathrm{h}$ than that at 10:00 $\mathrm{h}$, indicating that environmental factors at this time were not conducive to photosynthesis. When the male parent of Siza 3 was under stress at 12:00 h, the $P_{\mathrm{N}}$ did not decrease, indicating that the $P_{\mathrm{N}}$ of this variety was relatively stable. Therefore, there are differences in the diurnal variation in the $P_{\mathrm{N}}$ between varieties. The higher the light intensity and $\mathrm{CO}_{2}$ concentration, the higher the photosynthetic rate. During the day, the change in the $P_{\mathrm{N}}$ of Zhongmiansuo 48 was essentially the same as that of its female parent, and there was no obvious $\mathrm{OH}$. However, the $P_{\mathrm{N}}$ of Siza 3 displayed obvious $\mathrm{OH}$ under different conditions. Under low-light intensities, the $P_{\mathrm{N}}$ of Siza 3 exhibited no obvious heterosis. The higher the light intensity, the stronger the heterosis on the $P_{\mathrm{N}}$. Therefore, during cotton growth, the sunnier the days are, the more $\mathrm{OH}$ of the $P_{\mathrm{N}}$ in Siza 3. The $R_{\mathrm{P}}$ and 
$R_{\mathrm{D}}$ affect the $P_{\mathrm{N}}$. The $R_{\mathrm{D}}$ of Siza 3 was higher than that of its parent, and the $R_{\mathrm{P}}$ was also lower, indicating a strong negative $\mathrm{OH}$. Leaf transpiration and the advantages of the $E$ and $g_{\mathrm{s}}$ of the hybrids may be a major reason for the superiority of the $P_{\mathrm{N}}$ (Zeng et al. 2012). The $P_{\mathrm{N}}, E$, and $g_{\mathrm{s}}$ of the two hybrids and their parents were essentially the same during the day. The $P_{\mathrm{N}}, g_{\mathrm{s}}$, and $E$ of Zhongmiansuo 48 and its parents did not display obvious $\mathrm{OH}$. Moreover, the $P_{\mathrm{N}}$, $g_{\text {s }}$, and $E$ of Siza 3 and its parents showed obvious $\mathrm{OH}$. The apparent heterosis of the $P_{\mathrm{N}}$ of Siza 3 may be related to the heterosis on the yield. The $P_{\mathrm{N}}$ of Xiangzamian 3 displayed an $\mathrm{OH}$ throughout the day, which is consistent with the findings for Siza 3 , but the $P_{\mathrm{N}}$ of Xiangzamian 3 was stronger under high-temperature and high-light conditions (Zeng et al. 2012). These results indicate that there is heterosis on the photosynthesis of upland cotton hybrids, and the heterosis differs for different combinations.

The higher the light intensity, the higher the $P_{\mathrm{N}}$. When the light intensity was higher than $500 \mu$ mol(photon) $\mathrm{m}^{-2} \mathrm{~s}^{-1}$, the $P_{\mathrm{N}}$ of each variety significantly differed. The difference in the photosynthetic rate of the different varieties occurred mainly under conditions of high-light intensity, and there was no significant difference in the photosynthetic rate between the different varieties under low-light intensity.

Effects of $\mathrm{CO}_{2}$ concentration on the $\mathrm{OH}$ effects on the photosynthetic rate: With the increase in $\mathrm{CO}_{2}$ concentration, the superiority of the $P_{\mathrm{N}}$ of Siza 3 gradually increased. Under low $\mathrm{CO}_{2}$ concentrations, the effects of changes in $\mathrm{CO}_{2}$ concentration on the superiority of the $P_{\mathrm{N}}$ were obvious. In addition, under low $\mathrm{CO}_{2}$ concentrations, the superior $g_{\mathrm{s}}$ of both Zhongmiansuo 48 and Siza 3 remained stable. When the $\mathrm{CO}_{2}$ concentration exceeded $1,000 \mu \mathrm{mol} \mathrm{mol}{ }^{-1}$, the advantageous and superior $g_{\mathrm{s}}$ of Siza 3 increased with increasing $\mathrm{CO}_{2}$ concentration. The superior $g_{\mathrm{s}}$ of Zhongmiansuo 48 exhibited a unimodal curve when the $\mathrm{CO}_{2}$ concentration ranged from 200-2,000 $\mu \mathrm{mol}$ $\mathrm{mol}^{-1}$, showing both positive and negative superiority. The heterosis on the $g_{\mathrm{s}}$ of the two hybrids was not obvious, indicating that $g_{\text {s }}$ plays a small role in the changes in $\mathrm{CO}_{2}$ concentration on the photosynthetic rate. The higher the $\mathrm{CO}_{2}$ concentration, the more obvious the superiority of the $P_{\mathrm{N}}$ of Siza 3. These results indicate that there is a significant difference in the photosynthetic rates of the different cotton varieties at this $\mathrm{CO}_{2}$ concentration. The $\mathrm{CO}_{2}$ concentration in the atmosphere is generally $400 \mathrm{ppm}$ (Khan and Rizvi 2020). At this $\mathrm{CO}_{2}$ concentration, the $P_{\mathrm{N}}$ of Siza 3 displays a clear $\mathrm{OH}$, and the $P_{\mathrm{N}}$ of Zhongmiansuo 48 displays no obvious $\mathrm{OH}$.

Relationship between $\mathrm{Chl}$ fluorescence parameters and OH: Photochemical quenching $\left(\mathrm{q}_{\mathrm{P}}\right)$, nonphotochemical quenching (NPQ), potential PSII activity $\left(\mathrm{F}_{\mathrm{v}} / \mathrm{F}_{0}\right)$, and $\mathrm{F}_{\mathrm{v}} / \mathrm{F}_{\mathrm{m}}$ are $\mathrm{Chl}$ fluorescence parameters often used for measuring heterosis (Banks 2017, Sonobe and Wang 2018). In this experiment, the $F_{0}$ tended to increase under stress conditions and displayed a negative $\mathrm{OH}$, which is consistent with previous results (Zhang et al. 2006). The $\mathrm{V}_{\mathrm{k}}$ also tended to increase under stress conditions, but the negative $\mathrm{OH}$ was lower. The correlation coefficients between the $\mathrm{OH}$ of both $\mathrm{F}_{0}$ and $\mathrm{V}_{\mathrm{k}}$ and $P_{\mathrm{N}}$ are -0.622 and -0.613 , respectively. The $\mathrm{PI}_{\mathrm{abs}}$ tended to decrease and displayed a negative $\mathrm{OH}$, but its correlation with $P_{\mathrm{N}}$ reached 0.845 . Under high temperature and high light, the $\mathrm{OH}$ of the $\mathrm{PI}_{\text {abs }}$ was highly correlated with the $P_{\mathrm{N}}$. The $\mathrm{OH}$ of the $P_{\mathrm{N}}$ of hybrid cotton can be predicted by measuring the $\mathrm{PI}_{\mathrm{abs}}$ under high temperature and high light.

The $P_{\mathrm{N}}$ was the highest at 10:00 h, indicating that the environmental conditions were more suitable for photosynthesis of leaves at that time than at other times, and the fluorescence parameters of the different varieties did not differ significantly at this time. At 12:00 h, the $P_{\mathrm{N}}$ significantly decreased, indicating that the temperature and light at this time were stressful, which had a suppressive effect on photosynthesis. At 12:00 h, the $\mathrm{F}_{0}$ increased, the $\mathrm{PI}_{\mathrm{abs}}$ decreased significantly, the electron transport rate decreased, the $\mathrm{V}_{\mathrm{k}}$ increased, and the oxygen-evolving complex was damaged to some extent. This shows that under stress conditions, the decrease in the $P_{\mathrm{N}}$ and the changes in the $\mathrm{F}_{0}, \mathrm{PI}_{\mathrm{abs}}$, and $\mathrm{V}_{\mathrm{k}}$ occurred simultaneously. Since determining fluorescence parameters is more convenient than using an LI-6400 instrument, the change in fluorescence parameters in cotton leaves during the day should be measured. Changes in key parameters such as the $\mathrm{F}_{0}, \mathrm{~V}_{\mathrm{k}}$, and $\mathrm{PI}_{\mathrm{abs}}$ during stress conditions are more suitable for rapid evaluation of photosynthetic traits and their superiority in hybrid cotton.

Conclusion: The photosynthesis parameters of Zhongmiansuo 48 in the different environments did not display obvious $\mathrm{OH}$, but the $P_{\mathrm{N}}$ of Siza 3 was higher than that of Zhongmiansuo 48. In addition, the $\mathrm{PI}_{\mathrm{abs}}$ of Siza 3 was higher than that of Zhongmiansuo 48, indicating that Siza 3 has a higher electron transport ability. The $\mathrm{PI}_{\mathrm{abs}}$ was significantly related to the $\mathrm{OH}$ of the $P_{\mathrm{N}}$. Overall, the $\mathrm{OH}$ of the $P_{\mathrm{N}}$ of hybrid cotton can be predicted by measuring the $\mathrm{PI}_{\mathrm{abs}}$ under high-temperature and high-light conditions.

\section{References}

Banks J.M.: Continuous excitation chlorophyll fluorescence parameters: a review for practitioners. - Tree Physiol. 37: 1128-1136, 2017.

Biber P.D.: Leaf wand for measuring chlorophyll fluorescence on cylindrical leaves and its application on Juncus roemerianus (black needlerush). - Am. J. Plant Sci. 3: 75-83, 2012.

Chaves M.M., Flexas J., Pinheiro C.: Photosynthesis under drought and salt stress: regulation mechanisms from whole plant to cell. - Ann. Bot. -London 103: 551-560, 2009.

$\mathrm{Fu}$ W., Shen Y., Hao J. et al.: Acyl-CoA N-acyltransferase influences fertility by regulating lipid metabolism and jasmonic acid biogenesis in cotton. - Sci. Rep.-UK 5: 11790, 2015.

Ge Y., Li W., Liu Y.G. et al.: [Heterosis studies on photosynthetic and physiological performance of the subtending leaf of cotton boll of CCRI 63.] - Cotton Sci. 28: 250-259, 2016. [In Chinese] doi: 10.11963/issn.1002-7807.201603008.

Georgieva K., Yordanov I.: Temperature dependence of chlorophyll fluorescence parameters of pea seedlings. - J. Plant Physiol. 142: 151-155, 1993.

Khan M.R., Rizvi T.F.: Effect of elevated levels of $\mathrm{CO}_{2}$ on 
powdery mildew development in five cucurbit species. - Sci. Rep.-UK 10: 4986, 2020.

Li P.M., Gao H.Y., Strasser R.J.: [Application of fast chlorophyll fluorescence induction kinetic analysis in photosynthesis research.] - J. Plant Physiol. Mol. Biol. 31: 559-566, 2005. [In Chinese] doi: 10.3321/j.issn:1671-3877.2005.06.001.

Liu Z.W., Zhang P., Wang R. et al.: [Effects of soil progressive drought during the flowering and boll-forming stage on gas exchange parameters and chlorophyll fluorescence characteristics of the subtending leaf to cotton boll.] - Chin. J. Appl. Ecol. 25: 3533-3539, 2014. [In Chinese] doi: 10.13287/ j.1001-9332.20141010.010.

Sonobe R., Wang Q.: Assessing hyperspectral indices for tracing chlorophyll fluorescence parameters in deciduous forests. J. Environ. Manage. 227: 172-180, 2018.

von Caemmerer S., Lawson T., Oxborough K. et al:: Stomata conductance does not correlate with photosynthetic capacity in transgenic tobacco with reduced amounts of Rubisco. J. Exp. Bot. 55: 1157-1166, 2004.

Wang H., Chen Y., Hu W. et al.: Carbohydrate metabolism in the subtending leaf cross-acclimates to waterlogging and elevated temperature stress and influences boll biomass in cotton (Gossypium hirsutum). - Physiol. Plantarum 161: 339-354, 2017.

Wang Q., Liu N., Yang X. et al:: Small RNA-mediated responses to low- and high-temperature stresses in cotton. - Sci. Rep.-UK 6: 35558, 2016.

Wu J.Y., Lian W.J., Liu Z.G. et al.: [Evaluation of high temperature response and heat resistance of chlorophyll fluorescence parameters of different grape varieties.] - J. Northwest A \& F
Univ. 47: 80-88, 2019. [In Chinese] doi: 10.13207/j.cnki. jnwafu.2019.06.011.

Xing Y.H.: [The development process of Chinese hybrid cotton entering production.] - China Cotton 34: 7-10, 2007. [In Chinese] doi: 10.3969/j.issn.1000-632X.2007.12.003.

Xu Z., Zhou G., Shimizu H.: Plant responses to drought and rewatering. - Plant Signal. Behav. 5: 649-654, 2010.

Ye Z.P., Yu Q.: [Comparison between a new model of photosynthetic light response and traditional model.] J. Shenyang Agric. Univ. 38: 771-775, 2007. [In Chinese] doi: 10.3969/j.issn.1000-1700.2007.06.001.

Ye Z.P., Yu Q.: [Comparison of the response curves of photosynthesis to intercellular and atmospheric $\mathrm{CO}_{2}$.] Acta Ecol. Sin. 11: 2233-2238, 2009. [In Chinese] doi: CNKI:SUN:STXZ.0.2009-11-013.

Zeng B., Xu X., Zhou S. et al.: Effects of temperature and light on photosynthetic heterosis of an upland cotton hybrid cultivar. Crop Sci. 52: 282-291, 2012.

Zhang C.M., Wang X.Y., Yang F. et al.: [Application of chlorophyll fluorescence characteristics in the prediction of cotton heterosis.] - Xinjiang Agric. Sci. 43: 171-174, 2006. [In Chinese] doi: 10.3969/j.issn.1001-4330.2006.03.002.

Zhao X.G., Zhang Y.W., Guan Z.B. et al.: [Diurnal characteristics of heterosis of photosynthetic characteristics in Brassica napus.] - Northwest Agric. J. 26: 574-582, 2017. [In Chinese] doi: 10.7606/j.issn.1004-1389.2017.04.012.

Zhu X., Ai N.J., Zhang Y. et al.: Relationships between differential gene expression and heterosis in cotton hybrids developed from the foundation parent CRI-12 and its pedigree-derived lines. - Plant Sci. 180: 221-227, 2011.

(C) The authors. This is an open access article distributed under the terms of the Creative Commons BY-NC-ND Licence. 